\title{
Did compulsory wear regulations increase personal flotation device (PFD) use by boaters in small power recreational vessels? A before-after observational study conducted in Victoria, Australia
}

\author{
Erin Cassell, Stuart Newstead
}

Monash Injury Research Institute, Monash University (Clayton Campus), Clayton, Victoria, Australia

\section{Correspondence to} Erin Cassell, Monash Injury Research Institute, Building 70, Monash University (Clayton Campus), Clayton, Victoria 3800, Australia; erin.cassell@monash.edu

Received 16 January 2014 Revised 2 May 2014 Accepted 6 May 2014 Published Online First 2 June 2014

\begin{abstract}
Objective To estimate the effect of the 2005 Victorian mandatory personal flotation device (PFD) wearing regulations on PFD use by occupants of small (hull length $\leq 4.8 \mathrm{~m}$ ) power recreational vessels.

Design Before-after observational study investigating the probability of PFD use among occupants of small vessels before and after the regulations were introduced compared with the probability of use by their counterparts on large power vessels (hull length $>4.8-$ $12 \mathrm{~m}$ ) who were not required to wear PFDs before or after the regulations were introduced in the low-risk conditions in which observations occurred.
\end{abstract}

Methods Statewide observation surveys of boaters were conducted in peak boating periods between January and March 2005 (prelegislation) and 2007 (postlegislation). Data collection included size of vessel, age and sex of boaters, life jacket use, boat type, activity of boaters, type of waterway and weather and water conditions. Logistic regression modelling tested whether there were statistically significant differences in the change in the relative odds of occupants wearing PFDs from the preintervention to the postintervention period in small compared with large power recreational vessels.

Results The probability of PFD use increased from $22 \%$ to $63 \%$ on small power vessels compared with $12 \%$ to $13 \%$ on large vessels. Regression analysis showed a high statistically significant increase in the odds of PFD use on small vessels relative to large vessels (OR 6.2, $95 \% \mathrm{Cl} 4.2$ to $9.3, p<0.001)$. No statistically significant effect on use on large vessels was associated with the regulation (OR 1.27, 95\% Cl 0.94 to $1.70, p=0.15)$. Relative to large vessels, on small vessels the odds of PFD use increased significantly in both sexes, all age groups, all vessel types and activity groupings except for towed water sports where the increase was only marginally statistically significant.

Conclusions The legislative intervention was successful in increasing PFD wearing in small vessels. However, visible enforcement and tougher penalties are needed to optimise compliance.

\section{INTRODUCTION}

Recreational boaters form a substantial proportion of drowning deaths in Australia, ${ }^{1}$ the USA, ${ }^{2}$ Canada $^{3}$ and European countries. ${ }^{4}$ Personal flotation devices (PFDs), commonly called life jackets or life vests, are designed to prevent drowning by keeping the wearer afloat thereby increasing the likelihood of survival and rescue. A recent US matched cohort study estimated that over half of unintentional boating drowning deaths might be prevented by the use of life jackets, ${ }^{5}$ but studies conducted at state and national levels in the USA have shown that life jacket use by adult boaters is persistently low $(<31 \%$ in Washington State and $13 \%$ nationally), despite education and promotional campaigns to increase wearing rates. ${ }^{4}{ }^{6-8}$ The evaluation of the Life Jacket Saves Lives campaign conducted in Victoria, Australia in the summer of 2002/2003 failed to lift adult PFD wearing use on power vessels from the precampaign level of $13 \%{ }^{9}$

The term personal flotation device (PFD), as used in Australia, encompasses life jackets and buoyancy vests. PFDs are graded into three categories: PFD Type 1 (Standards-approved life jackets); PFD Type 2 (Standards-approved buoyancy vests in defined high visibility colours); and PFD Type 3 (Standards-approved buoyancy vests in other than high visibility colours). ${ }^{10}$ The type of PFD to be carried and worn on recreational vessels is under the control of state and territory marine authorities.

In late 2005, Victoria (population 5.5 million) became the second jurisdiction in the world following Tasmania, the smallest Australian state, to introduce broad-based regulations mandating PFD wearing for recreational boaters. ${ }^{10}$ Under the pre-2005 Victorian marine safety regulations, all power recreational vessels had to carry sufficient PFDs for every occupant on board. PFD use was compulsory for children aged less than 10 years and for persons being towed and, in effect, for PWC (personal watercraft/jet ski) riders as there was no room to stow PFDs on these vessels.

A major influence on the decision to strengthen Victorian regulations was the State Coroner's recommendation in 2003 that the marine regulator (Marine Safety Victoria-MSV) make PFD wearing mandatory for all occupants of recreational vessels at all times. ${ }^{11}$ The Coroner's statement followed the release of an in-depth coronial study of the 40 recreational boating-related drowning deaths from 30 separate incidents that occurred in Victorian waters between 1999 and 2002. ${ }^{12}$ The study found that, in most instances, the non-carriage of PFDs or failure to use them (mostly due to sudden immersion) was a major contributor to fatal drowning. ${ }^{12}$ Ninety per cent of fatal incidents involved motorised vessels, mostly $<6 \mathrm{~m}$ in length. ${ }^{11} 12$

These findings, the Coroner's recommendation and the unsuccessful 2002/2003 Life Jackets Save Lives campaign prompted the Victorian government to introduce broad-based mandatory PFD wearing regulations for recreational boaters on 1 
December 2005. ${ }^{11}$ The new regulations required all occupants of recreational vessels to wear specified types of approved PFDs at defined times. ${ }^{10}$ Occupants of 'small' recreational vesselsdefined as vessels $\leq 4.8 \mathrm{~m} \mathrm{(} \mathrm{16} \mathrm{feet)} \mathrm{in} \mathrm{hull} \mathrm{length-were}$ required to wear a PFD when in an open area of the vessel when the vessel was underway. Vessels covered included all power-driven vessels, off-the-beach sailing yachts (dinghies), PWC (jet skis) and non-motorised vessels such as canoes, kayaks, rowing boats, kite boards and sailboards. Occupants of 'large' recreational vessels-defined as power-driven vessels and yachts $<4.8-12 \mathrm{~m}$ in hull length-were required to wear a PFD when underway at defined times of heightened risk such as when crossing a bar, operating a vessel alone or at night, and when a gale, storm or severe weather warning has been issued by the Bureau of Meteorology. The type of PFD to be worn (1, 2 or 3) was specified for each vessel type and waterway classification (inland, enclosed and coastal). 'Underway' was defined as not being at anchor, made fast to shore or aground and included drifting.

In Victoria the boating 'season' runs from October to March, with peak use of recreational vessels in the summer vacation break (January) through weekends and public holidays to the end of March or Easter if later. Our study sought to evaluate the effectiveness of the 2005 Victorian regulations by estimating the probability of PFD use by recreational boaters in the peak months of boating season 2005 (8-10 months preregulation) compared with the peak months of boating season 2007 (13-15 months postregulation). Boaters in small recreational vessels, the main target of the expanded mandatory PFD wear regulations, were the designated intervention group. Boaters on large vessels formed the comparison group because they were not required to wear PFDs in the environment (setting out and coming into boat ramps) and conditions (fine weather) under which the observations took place. The use of a comparison group provides evidence that any observed increases in PFD wearing in the intervention group were due to the regulations not to natural temporal trends or concurrent interventions/ events.

\section{METHODS}

Direct observation was used to investigate whether the probability of PFD use among occupants of small and large vessels increased after the mandatory regulations came into force for all vessel occupants and stratified by gender, age, trip purpose (activity of boater) and vessel type.

\section{Setting}

We initially selected the 42 boat ramps designated high priority (based on usage, risky conditions for boating and geographical spread) on the list of 78 known ramps compiled by MSV for a boating safety billboard campaign in 2002/2003. They were located in popular freshwater (lake and river) and saltwater (bay) boating locations in the six Victorian metropolitan and rural regions. This number was reduced to 36 in the study planning phase for logistical reasons, and further minor adjustments were made in each observation year (see below). One 2-h observation session, conducted by a single observer, was held at each site during the peak vessel use periods described above, with each observer usually covering two sites during daylight hours depending on travel time between sites.

\section{Data collection}

In both years observers underwent a standardised 4-h training session, including onsite practical training. Observation points were all shore-based and were chosen to provide good visibility of the ramp, vessels and their occupants. Observers marked out $4.8 \mathrm{~m}$ on the side of the ramp before each session.

The observer recorded PFD wearing using adaptations of site and boater forms used in previous studies. ${ }^{46}$ Site form variables included: location, start time and end time of session, day of the week, weather, wind and water conditions and visibility at start and end of session. Boat and boater observation form variables included: estimated age and gender of boater, direction of travel, vessel type and estimated length, purpose of the trip, number of persons on board, their PFD use and the PFD type worn.

\section{Data analysis}

Preliminary analysis used logistic regression modelling to calculate the change in odds of PFD use before and after the legislation among occupants of small and large vessels separately and to measure the statistical significance of the change in odds. The main analysis used logistic regression to compare the change in odds of PFD wearing from prelegislation to postlegislation for occupants of small vessels versus large vessels. The primary analysis determined whether the effect of the legislation was significantly higher in the intervention compared with the comparison group, overall and within particular demographic, vessel type and vessel use strata. Analysis was conducted using SPSS V.17.0.

\section{RESULTS}

In 2005, 2682 boaters were observed in 1074 small and large vessels over the $342-\mathrm{h}$ observation sessions, excluding 85 records due to missing data on PFD use or vessel length (table 1). In 2007, 2347 boaters were observed in 918 vessels over 32 2-h sessions (excluding 30 records due to missing data as above), 20\% fewer boaters and $15 \%$ fewer vessels than observed in 2005. However, the proportions of observed boaters on small and large vessels were the same and boater profiles were similar.

\section{PFD use: before and after regulations}

Among all occupants of small power vessels PFD use increased by 41 percentage points from $22 \%$ in 2005 to $63 \%$ in 2007 , with large increases observed in men (41 percentage points), women (39 percentage points), all age groups (range 23 percentage points increase among children 0-9 years to 56 percentage points increase among adults aged 60 years and older), sole operators (47 percentage points), occupants of open boats (50 percentage points), fishers (53 percentage points) and boaters pleasure cruising/engaged in general boating activity (38 percentage points) (figure 1). The results of the PFD usage survey conducted in 2006 from January to March are included and show that the increases in PFD use began in almost all groups of boaters shortly after the regulations came into force; 2006 was regarded as a transition year as implementation of the mandatory regulations was postponed by the government from 1 July 2005 to 1 December 2005 (the middle of the boating season in Victoria) causing public confusion.

By contrast, there was little change in PFD use among all boaters on large vessels between 2005 (12\%) and 2007 (13\%), and among men, adults aged 18-59 years, occupants of half cabin vessels, occupants of ski boats and persons engaged in towed water sports and high- speed racing (not shown). There were small increases or decreases (between 1 and 5 percentage points) in PFD use among all other groups studied except for children and adolescents among whom wear increased by 7 and 10 percentage points respectively, and yachtpersons among whom wear decreased by 17 percentage points (not shown). 
Table 1 Comparison of the profile of boaters, trip purpose (boater activity) and power vessel types observed in the preobservation (2005)/ postobservation (2007) periods for small (S) and large (L) vessels

\begin{tabular}{|c|c|c|c|c|c|}
\hline & \multirow[b]{2}{*}{ Vessel length } & \multicolumn{2}{|c|}{ Preregulation profile (2005) } & \multicolumn{2}{|c|}{ Postregulation profile (2007) } \\
\hline & & $\mathrm{N}$ & Per cent & $\mathbf{N}$ & Per cent \\
\hline \multicolumn{6}{|l|}{ Number of observed boaters } \\
\hline & S & 1196 & 44.6 & 1062 & 45.2 \\
\hline & L & 1486 & 55.4 & 1285 & 54.8 \\
\hline \multicolumn{6}{|l|}{ Gender } \\
\hline \multirow[t]{2}{*}{ Male } & $s$ & 977 & 81.7 & 853 & 80.3 \\
\hline & L & 1130 & 76.0 & 929 & 72.3 \\
\hline \multirow[t]{2}{*}{ Female } & s & 212 & 17.7 & 199 & 18.7 \\
\hline & L & 350 & 23.6 & 353 & 27.5 \\
\hline \multirow[t]{2}{*}{ Undetermined } & $s$ & 7 & 0.6 & 10 & 0.9 \\
\hline & L & 6 & 0.4 & 3 & 0.2 \\
\hline \multicolumn{6}{|l|}{ Age group } \\
\hline \multirow[t]{2}{*}{$0-9$ years } & $s$ & 110 & 9.2 & 84 & 7.9 \\
\hline & $\mathrm{L}$ & 135 & 9.1 & 110 & 8.6 \\
\hline \multirow[t]{2}{*}{$10-17$ years } & s & 165 & 13.8 & 132 & 12.4 \\
\hline & L & 183 & 12.3 & 118 & 9.2 \\
\hline \multirow[t]{2}{*}{$18-59$ years } & $s$ & 813 & 68.0 & 773 & 72.8 \\
\hline & L & 1041 & 70.1 & 971 & 75.6 \\
\hline \multirow[t]{2}{*}{60 years and older } & $s$ & 100 & 8.4 & 65 & 6.1 \\
\hline & L & 121 & 8.1 & 78 & 6.1 \\
\hline \multirow[t]{2}{*}{ Undetermined } & s & 8 & 0.7 & 8 & 0.8 \\
\hline & L & 6 & 0.4 & 8 & 0.6 \\
\hline \multicolumn{6}{|l|}{ Type of vessel } \\
\hline \multirow[t]{2}{*}{ Open/'tinny' } & $s$ & 565 & 47.2 & 577 & 54.3 \\
\hline & L & 320 & 21.5 & 313 & 24.4 \\
\hline \multirow[t]{2}{*}{ Cuddy/half cabin cruiser } & s & 340 & 28.4 & 222 & 20.9 \\
\hline & L & 636 & 42.8 & 459 & 35.7 \\
\hline \multirow[t]{2}{*}{ Full cabin cruiser } & $s$ & 20 & 1.7 & 19 & 1.8 \\
\hline & L & 191 & 12.9 & 169 & 13.2 \\
\hline \multirow[t]{2}{*}{ Ski boat } & S & 45 & 3.8 & 39 & 3.7 \\
\hline & L & 194 & 13.1 & 229 & 17.8 \\
\hline PWC & S & 163 & 13.6 & 166 & 15.6 \\
\hline & L & - & - & 10 & 0.8 \\
\hline Yacht (motor/trailer sailer) & S & 3 & 0.3 & - & - \\
\hline & L & 67 & 4.5 & 86 & 6.7 \\
\hline Other/unknown & s & 60 & 5.0 & 39 & 3.7 \\
\hline & L & 78 & 5.2 & 29 & 2.3 \\
\hline Trip purpose (activity of boate & & & & & \\
\hline Fishing & $s$ & 562 & 47.0 & 489 & 46.0 \\
\hline & L & 637 & 42.9 & 534 & 41.6 \\
\hline Towed water sports & $s$ & 41 & 3.4 & 69 & 6.5 \\
\hline & L & 187 & 12.6 & 135 & 10.5 \\
\hline Pleasure cruising/general & s & 381 & 31.9 & 287 & 27.0 \\
\hline & L & 501 & 33.7 & 438 & 34.1 \\
\hline High speed/racing & $s$ & 8 & 0.7 & 6 & 0.6 \\
\hline & L & 38 & 2.6 & 34 & 2.6 \\
\hline PWC riding & S & 163 & 13.6 & 161 & 15.2 \\
\hline & L & - & - & - & - \\
\hline Sailing & s & 3 & 0.3 & - & - \\
\hline & L & 67 & 4.5 & 86 & 6.7 \\
\hline Other & $S$ & 30 & 2.5 & 39 & 3.7 \\
\hline & L & 30 & 2.0 & 41 & 3.2 \\
\hline Missing & $S$ & 8 & 0.7 & 11 & 1.0 \\
\hline & L & 26 & 1.7 & 17 & 1.3 \\
\hline
\end{tabular}

PWC, personal watercraft/jet ski. 


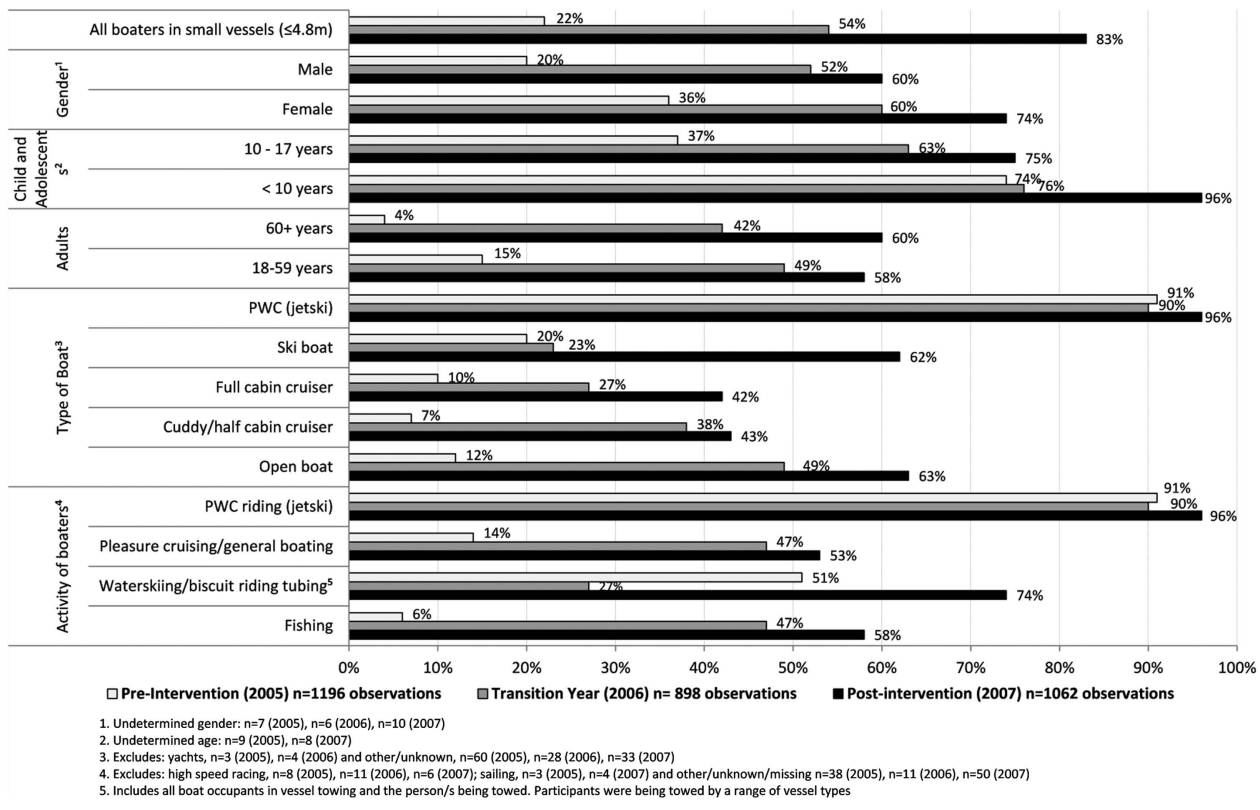

Figure 1 PFD use among boaters on small recreational power vessels by demographics, type of vessel and activity of boaters before and after the 2005 PFD wearing regulations. PFD, personal flotation device.

\section{PFD use: preliminary logistic regression analysis}

Regression analysis results in table 2 indicate a high statistically significant eightfold increase in the odds of PFD use among all occupants of small vessels between 2005 and 2007, with significant and similarly sized increases in the odds of use observed among male and female boaters and in those aged 18-59 years who comprised around $70 \%$ of observed boaters in small (and large) vessels. There were significant increases in the odds of PFD use in small vessels for all other age groups, the highest increase (33.5-fold) observed among boaters aged 60 years and older and lowest (5.7-fold) among adolescents aged 10-17 years (table 2).

Open boats and cuddies/half cabin cruisers accounted for $75 \%$ of small and large vessels observed in the presurveys and postsurveys. For small vessels there were high statistically significant increases in the odds of occupants of both these types of vessels using PFDs between 2005 and 2007 (table 2). The odds of PFD use among occupants of small open boats increased 27.7-fold and the odds of use by occupants of cuddies/half cabin cruiser vessels increased 26.3-fold. Significant increases in the odds of PFD use were also observed among occupants of small ski boats (including persons being towed), PWC and 'other' vessels. Change in PFD wearing among occupants of yachts could not be estimated due to small numbers.

About three quarters of observed boaters in small and large vessels were engaged in fishing and pleasure cruising/general boating. For small vessels between 2005 and 2007, there was a 60.4-fold increase in the odds of PFD use among fishers on small vessels and an 18.4-fold increase in odds of use among pleasure cruisers/general boaters (table 2). The odds of PFD use also increased significantly among occupants of small vessels engaged in towed water sports and riding PWCs.

There were no statistically significant increases in the odds of PFD use between 2005 and 2007 in the comparison groupoccupants of large vessels-overall (OR 1.27, 95\% CI 0.94 to $1.70, \mathrm{p}=0.15)$ and by gender and in all age groups except adolescents among whom the odds of PFD wear increased significantly (OR $1.73,95 \%$ CI 1.01 to $2.97, \mathrm{p}=0.05$ ) (table 2 ).
Small, non-significant increases in the odds of wear were observed among boaters engaged in fishing and pleasure cruising/general boating (the two major activity types) and by participants in towed water sports. The odds of yachtspersons wearing PFDs declined significantly between 2005 and 2007 (OR 0.38, $95 \%$ CI 0.14 to $0.10, \mathrm{p}=0.05)$. There was no significant change in the odds of occupants of cuddies/half cabin cruisers (the major large vessel type) and ski boats wearing PFDs and decreased wearing odds of occupants of full cabin cruisers and yachts (as mentioned above). However, there was a statistically significant doubling in the odds of occupants of large open vessels wearing PFDs (OR 2.01, 95\% CI 1.04 to 3.89, $\mathrm{p}=0.039)$.

\section{Primary analysis}

Table 3 shows the change in odds of PFD use among occupants of small vessels (overall and in all subgroups) from before to after the 2005 regulations compared with parallel changes in the odds of PFD use in the large vessel occupant groups. There were significantly higher effects in relation to changes in the odds of PFD use in the intervention than the comparison groups for all analyses. Cell numbers for some groups were too small to make estimations. The only exceptions were for other and unknown vessel type and trip purpose and for towed water sports where the relative change was only marginally statistically significant $(p=0.061)$. The relative change in odds for each of these groups was still less than 3 with the lack of statistical significance being partly a reflection of the smaller number of small vessel observations in these groups.

\section{DISCUSSION}

Analysis results demonstrate a high statistically significant eightfold increase in the odds of PFD use by boaters on small power recreational vessels following the 2005 PFD wearing legislation in Victoria compared with a negligible and nonsignificant increase in the odds of PFD use by boaters on large power vessels who were mostly not required to wear PFDs in the environment and conditions in which the observations 
Table 2 Logistic regression model of PFD use by boaters on small and large recreational power vessels before and after the implementation of the 2005 Victorian mandatory PFD wear regulations, overall and by gender, age, vessel type and trip purpose (activity of boater)

\begin{tabular}{|c|c|c|c|c|c|c|}
\hline \multirow[b]{2}{*}{ Strata } & \multirow[b]{2}{*}{ Level } & \multirow[b]{2}{*}{ Vessel length } & \multirow{2}{*}{$\begin{array}{l}\text { Odds of PFD wear after the } \\
2005 \text { regulations versus before }\end{array}$} & \multicolumn{2}{|l|}{$95 \% \mathrm{Cl}$} & \multirow[b]{2}{*}{ Stat. Sig. } \\
\hline & & & & Lower & Upper & \\
\hline \multicolumn{7}{|c|}{ All vessel occupants } \\
\hline & \multirow[t]{2}{*}{ All } & $s$ & 8.173 & 6.612 & 10.103 & $<0.001$ \\
\hline & & $L$ & 1.267 & 0.943 & 1.703 & 0.116 \\
\hline \multicolumn{7}{|l|}{ Gender } \\
\hline & \multirow[t]{2}{*}{ Male } & $\mathrm{s}$ & 8.223 & 6.504 & 10.396 & $<0.001$ \\
\hline & & $L$ & 1.381 & 0.951 & 2.006 & 0.090 \\
\hline & \multirow[t]{2}{*}{ Female } & $S$ & 7.952 & 4.844 & 13.054 & $<0.001$ \\
\hline & & $L$ & 1.096 & 0.675 & 1.778 & 0.711 \\
\hline \multicolumn{7}{|l|}{ Age } \\
\hline & \multirow[t]{2}{*}{$0-9$ years } & $s$ & 8.776 & 2.550 & 30.200 & 0.001 \\
\hline & & $L$ & 1.235 & 0.657 & 2.321 & 0.513 \\
\hline & \multirow[t]{2}{*}{$10-17$ years } & S & 5.685 & 3.359 & 9.621 & $<0.001$ \\
\hline & & $L$ & 1.730 & 1.006 & 2.973 & 0.047 \\
\hline & \multirow[t]{2}{*}{$18-59$ years } & $S$ & 7.983 & 6.263 & 10.177 & $<0.001$ \\
\hline & & $L$ & 1.126 & 0.724 & 1.752 & 0.598 \\
\hline & \multirow[t]{2}{*}{$60+$ years } & $S$ & 33.560 & 10.893 & 103.391 & $<0.001$ \\
\hline & & $L$ & 0.522 & 0.102 & 2.673 & 0.435 \\
\hline \multicolumn{7}{|c|}{ Type of vessel } \\
\hline & \multirow[t]{2}{*}{ Open } & $s$ & 27.705 & 17.772 & 43.189 & $<0.001$ \\
\hline & & $L$ & 2.008 & 1.035 & 3.895 & 0.039 \\
\hline & \multirow[t]{2}{*}{ Cuddy/half cabin cruiser } & $S$ & 26.278 & 12.665 & 54.522 & $<0.001$ \\
\hline & & $L$ & 1.168 & 0.655 & 2.083 & 0.599 \\
\hline & \multirow[t]{2}{*}{ Full cabin cruiser } & $s$ & & & & \\
\hline & & $L$ & 0.544 & 0.172 & 1.718 & 0.299 \\
\hline & \multirow[t]{2}{*}{ Ski boat } & $S$ & 27.485 & 4.504 & 167.716 & $<0.001$ \\
\hline & & $L$ & 1.214 & 0.645 & 2.282 & 0.548 \\
\hline & PWC & s & 2.648 & 1.030 & 6.805 & 0.043 \\
\hline & & $L$ & & & & \\
\hline & Yacht (motor/trailer sailor) & $S$ & & & & \\
\hline & & $L$ & 0.212 & 0.072 & 0.626 & 0.005 \\
\hline & Other/unknown & $S$ & 6.882 & 2.327 & 20.352 & $<0.001$ \\
\hline & & $L$ & 29.503 & 3.159 & 275.491 & 0.003 \\
\hline Trip pur & ivity of boater) & & & & & \\
\hline & Fishing & $s$ & 60.438 & 32.715 & 111.652 & $<0.001$ \\
\hline & & $L$ & 1.495 & 0.810 & 2.760 & 0.198 \\
\hline & Towed water sport & $s$ & 4.395 & 1.595 & 12.111 & 0.004 \\
\hline & & $L$ & 1.775 & 0.950 & 3.316 & 0.072 \\
\hline & Pleasure cruising/general & $S$ & 18.348 & 10.471 & 32.150 & $<0.001$ \\
\hline & & $L$ & 1.432 & 0.765 & 2.681 & 0.262 \\
\hline & High-speed racing & $S$ & & & & \\
\hline & & $L$ & & & & \\
\hline & PWC riding & $S$ & 2.612 & 1.016 & 6.717 & 0.046 \\
\hline & & $L$ & & & & \\
\hline & Sailing & $S$ & & & & \\
\hline & & $L$ & 0.378 & 0.143 & 0.996 & 0.049 \\
\hline & Other & S & 1.376 & 0.495 & 3.822 & 0.540 \\
\hline & & $L$ & 1.979 & 0.528 & 7.422 & 0.311 \\
\hline
\end{tabular}

Note: Empty cells indicate insufficient data to obtain estimate.

PFD, personal flotation device; PWC, personal watercraft/jet ski.

occurred (setting out or coming in to a boat ramp in fine weather with good visibility). The beneficial effect of the legislation in changing the PFD wearing behaviour of small vessel occupants was consistent in both sexes, among all age groups and for all boating activity groups and vessel types.

Although the behavioural effects of the legislation were significantly higher in the intervention than the comparison groups in all analyses, there were statistically significant increases in the odds of PFD use on large vessels for adolescents aged 10-17years and all boaters on open vessels. There are several possible explanations: (1) misclassification of age group and vessel size close to the classification change point; (2) heightened awareness of the increased risk of drowning of occupants of open boats generated by the release of the findings of the 2003 study of recreational vessel 
Table 3 Logistic regression model of PFD use after the 2005 regulations versus before among boaters on small recreational power vessels relative to boaters on large vessels, overall and by gender, age, vessel type and trip purpose

\begin{tabular}{|c|c|c|c|c|c|}
\hline \multirow[b]{2}{*}{ Strata } & \multirow[b]{2}{*}{ Level } & \multirow{2}{*}{$\begin{array}{l}\text { Odds of PFD wear after the } 2005 \\
\text { regulations versus before in small } \\
\text { vessels relative to large vessels }\end{array}$} & \multicolumn{2}{|l|}{$95 \% \mathrm{Cl}$} & \multirow{2}{*}{$\begin{array}{l}\text { Statistical } \\
\text { Significance }\end{array}$} \\
\hline & & & Lower & Upper & \\
\hline All & All & 6.200 & 4.157 & 9.247 & 0.000 \\
\hline \multicolumn{6}{|l|}{ Gender } \\
\hline & Male & 6.162 & 3.813 & 9.958 & 0.000 \\
\hline & Female & 6.287 & 3.052 & 12.949 & 0.000 \\
\hline \multicolumn{6}{|l|}{ Age } \\
\hline & $0-9$ years & 7.074 & 1.753 & 28.548 & 0.006 \\
\hline & 10-17 years & 3.281 & 1.536 & 7.010 & 0.002 \\
\hline & $18-59$ years & 6.783 & 4.047 & 11.369 & 0.000 \\
\hline & $60+$ years & 54.616 & 7.451 & 400.324 & 0.000 \\
\hline \multicolumn{6}{|c|}{ Type of vessel } \\
\hline & Open & 16.581 & 8.203 & 33.514 & 0.000 \\
\hline & Cuddy/half cabin cruiser & 24.648 & 10.926 & 55.601 & 0.000 \\
\hline & Full cabin cruiser & 21.903 & 2.118 & 226.526 & 0.010 \\
\hline & Ski boat & 11.903 & 3.208 & 44.171 & 0.000 \\
\hline & PWC & & & & \\
\hline & Yacht (motor/trailer sailer) & & & & \\
\hline & Other/unknown & 2.734 & 0.517 & 14.449 & 0.236 \\
\hline \multicolumn{6}{|c|}{ Trip purpose (activity of boater) } \\
\hline & Fishing & 45.013 & 21.431 & 94.545 & 0.000 \\
\hline & Towed water sports & 2.951 & 0.952 & 9.152 & 0.061 \\
\hline & Pleasure cruising/general & 15.043 & 7.319 & 30.920 & 0.000 \\
\hline & High-speed racing & & & & \\
\hline & PWC riding & & & & \\
\hline & Sailing & & & & \\
\hline & Other/unknown & 2.962 & 0.445 & 19.703 & 0.261 \\
\hline
\end{tabular}

Note: Empty cells indicate insufficient data to obtain estimate.

PFD, personal flotation device; PWC, personal watercraft/jet ski.

fatalities in Victoria; (3) the expanded and better targeted 2005/ 2006 MSV promotional campaign 'Get on board with life jackets' may have influenced parents to extend compulsory PFD wear to older children and occupants of large open vessels to don PFDs voluntarily; and (4) the approval of more comfortable clip and zip and inflatable style PFDs (that met specified overseas safety standards) in the 2005 Victorian legislation and their increased availability may have encouraged voluntary adoption.

The Tasmanian government did not formally evaluate whether their mandatory PFD wearing regulations had any effect on use. The other published report on the effectiveness of a regulatory approach targeting adult boaters describes a successful 3-year demonstration program conducted by the US Army Corps of Engineers. ${ }^{14}$ Mandatory PFD wear regulations were introduced for all boaters using four lakes in north-western Mississippi, supported by prepublicity and significant visible patrols. Adult wearing rates increased from $13.5 \%$ to $70.9 \%$ on average in the 3 years the regulations were active. ${ }^{14}$ The authors compared these results with the weak effects of the 'Wear it California!' targeted multistrategy marketing campaign that promoted voluntary life jacket/PFD wearing to adult boaters in the California Delta region. ${ }^{14}$ Adult wear increased from $8.5 \%$ (preintervention) to $10.5 \% 3+$ years after the campaign in Californian Delta region, with the peak adult wearing rate of $12.1 \%$ achieved during the first and most active year of the campaign. ${ }^{14}$ The authors recommend a combined strategy-regulation supported by education to gain public cooperation-to increase life jacket use in the USA. ${ }^{14}$
The prelegislation PFD wearing rate by occupants of small and large power vessels in Victoria in 2005 was 17\%. This figure is consistent with estimations reported from observational studies of PFD use by boaters conducted in 2007 in the four Australian states without comprehensive mandatory PFD wearing regulations (range $8-28 \%),{ }^{15}$ Canada (20\%), ${ }^{16}$ and the three Washington state and regional studies (17-21\% for motor boaters). ${ }^{468}$ The US 2012 national life jacket wear rate observational study reported that wearing rates among adults on powerboats was consistently low between 1999 and 2012 (range $3.9 \%$ to $5.2 \%)^{7}$ All these studies found higher PFD use in groups where use was mandatory such as children on boats, water-skiers and PWC riders. ${ }^{4}$ 6-8 1516

The current study showed an increase of 41 percentage points in PFD wear by boaters on small vessels 13-15 months after the introduction of the regulations, achieved with limited enforcement by authorities. MSV records show that Water Police issued only 30 infringement notices to non-compliant small vessel occupants between January and June, 2006 (Personal communication, Peter Corcoran, Director, Transport Safety VictoriaMaritime). MSV-employed Boating Safety Officers took an educational approach. Studies of the effectiveness of bicycle helmet wearing regulations, where enforcement is also reported to be uniformly low, provide supportive evidence that estimation in this study of the size of the effect is credible. ${ }^{17}$ Consistent with findings here, bicycle helmet use in Victoria increased by 37 percentage points 1 year after compulsory wear legislation came into effect. ${ }^{18}$ Increases of more than 30 percentage points in 
helmet wearing were reported from 7 of the 12 studies included in a systematic review of the effectiveness of bicycle helmet legislation that included the Victorian study. ${ }^{17}$

As evidenced by the lack of behaviour change observed among large vessel occupants for whom PFD wearing was voluntary in the setting in which they were observed, it is unlikely that the large increase in the odds of PFD wear by boaters on small vessels found in our study was heavily influenced by raised boating safety awareness through education and publicity or other unknown factors, independent of the legislative effect. The 2002/2003 Victorian Life Jackets Save Lives stand-alone education campaign did not change behaviour. ${ }^{9}$ The three other reports on the effectiveness of awareness-raising campaigns promoting PFD use to adult power boaters in regions of the USA found no or small (4-7 percentage point) increases in wear rates among power boaters. ${ }^{6714}$

However, the MSV-funded direct mail, press, radio and television PFD wear promotional campaign 'Get on board with life jackets' conducted from 1 December 2005 to Easter 2006, that alerted all recreational boaters of their PFD wearing obligations under the new regulations and promoted the newly approved more comfortable PFDs, appeared to have played an important supportive role to the legislation (http://www.lib.uts.edu/au/gta/ 14037/get-on-board-life-jackets, retrieved 14 May 2013). The 2006 postcampaign telephone survey of 401 vessel licence holders showed that half of the $84 \%$ of respondents who reported that they were aware of some recent changes in marine regulations identified, unprompted, that compulsory life jacket wear was the major change, increasing to $81 \%$ when prompted. ${ }^{20}$ The mailed-out brochure was the major information source (46\%), followed by newspaper (44\%), television (24\%) and radio (20\%) advertisements and publicity. ${ }^{20}$ Experience of regions implementing bicycle helmet and seat belt wearing legislation indicates that stand-alone education/public awareness campaigns have limited effect on protective equipment use but perform a necessary role in informing the community of their obligations under new safety legislation and a vital role in publicising enforcement programmes to maximise compliance. ${ }^{17} 19$

Potential study limitations exist. In 2007 attempts were made to adhere to the 2005 sessions schedule but bushfires in January 2007 , lake closures due to drought, inclement weather conditions and unavailability of observers on equivalent days/weekends led to some schedule adjustments. There were a similar number of observed boaters but fewer observations in the Eastern Zone and more in the Western Zone in 2007 compared with 2005. Some misclassification by observers of vessel length and age of children may have occurred but this was unlikely to have a time-based bias effect on the changes observed. The use of shore-based observers was also a potential limitation but on-water observation was not a good option as the likelihood of misclassification of vessel length would have increased considerably (several small power vessel models were close in length to the $4.8 \mathrm{~m}$ cut-off). Observer bias was also a possibility but the stability of the small observation team (three of the four members of the 2007 observation team were members of the 2005 team) and standardised on-site training sessions conducted in both years should have minimised this potential source of bias.

In summary, the 2005 Victorian compulsory PFD wearing regulations appear to be a powerful stimulant to behaviour change but additional resources are needed to increase visible enforcement activities given the less than full compliance with the regulations among small vessel occupants. The effectiveness of compulsory PFD wear legislation as a boater drowning prevention measure is the subject of a related study. ${ }^{21}$

\section{What is already known on the subject}

- Recreational vessel occupants comprise a sizeable proportion of drowning deaths in Australia and other high-income countries.

- Personal flotation devices (PFDs) are designed to keep the wearer afloat to increase the likelihood of rescue and reduce drowning risk.

- Voluntary PFD use has been promoted to boaters in Australia and elsewhere with limited impact on wear rates, especially among adults.

\section{What this study adds}

- This is the first evaluation study of the effectiveness of mandatory PFD wearing regulations on use by recreational boaters.

- Victoria (Australia) introduced broad-based compulsory PFD wearing regulations for recreational boaters in late 2005, the second jurisdiction in the world to do so.

- The current before and after observational study found that upon introduction of the regulations in 2005, PFD use among boaters increased from $22 \%$ to $63 \%$ on small power vessels (the intervention group) compared with $12 \%$ to $13 \%$ on large vessels (the comparison group).

- Regression analysis showed a high statistically significant eightfold increase in the odds of PFD use by boaters on small power recreational vessels following the 2005 PFD wearing legislation in Victoria compared with a negligible and statistically non-significant increase in the odds of PFD use by boaters on large power vessels.

- The beneficial effect of the legislation in changing the PFD wearing behaviour of small vessel occupants was consistent in both sexes, among all age groups and for all boating activity groups and vessel types.

Acknowledgements The authors thank the observation team members (lan Morrison, Jonathon Guy, Narelle Hayes, Melinda Congiu, Angela Clapperton, Karen Ashby and Barbara Fox) for their contribution to the research.

Contributors EC conceived of the study and its design, with input from SN on statistical analysis. Both authors contributed to data analysis, interpretation, manuscript development and revision and final approval.

Funding This research including salary of EC was funded by Marine Safety Victoria (MSV), now a section of Transport Safety Victoria (TSV). Grant: W04006 - 4598205.

Competing interests None.

Ethics approval Monash University Standing Committee on Ethics in Human Research.

Provenance and peer review Not commissioned; externally peer reviewed.

\section{REFERENCES}

1 Royal Life Saving Society-Australia. National drowning report 2013. RLSSA, 2013. http://www.royallifesaving.com.au/RLS_NationalDrowningReport_2013[1].pdf (accessed 16 Apr 2014).

2 Centres for Disease Control and Prevention. Drowning-United States, 2005-9. MMWR Morb Mortal Wkly Rep 2012;61:344-7.

3 Transport Canada and Canadian Red Cross. Boating immersion and marine deaths in Canada. 18 years of research. Transport Canada and The Red Cross Society, 2011. http://www.redcross.ca/crcdocumenrs/3-3-4-_2011_boating_fnl.pdf (accessed 16 Apr 2014). 
4 Quan L, Bennett E, Cummings $\mathrm{P}$, et al. Are life vests worn? A multiregional observational study of personal flotation device use in small boats. Inj Prev 1998;4:203-5.

5 Cummings P, Mueller BA, Quan L. Association between wearing a personal floatation device and death by drowning among recreational boaters: a matched cohort analysis of United States Coast Guard data. Inj Prev 2010;17:156-9.

6 Treser C, Trusty M, Yang P. Personal flotation device usage: do educational efforts have an impact? J Public Health Policy 1997;18:346-56.

7 Mangione TW, Imre M, Chow W, et al. 2012 life jacket wear observation study featuring national wear rate data from 1999 to 2012. Boston, Massachusetts: JSI Research and Training Institute, 2013.

8 Chung C, Quan L, Bennett E, et al. Informing policy on open water drowning prevention: an observational survey of life jacket use in Washington state. Inj Prev 2014;20:238-43.

9 Quantum Market Research. Life jacket and licensing campaign evaluations. Wave 2 report quantitative findings. Report to Marine Safety Victoria. Melbourne, February 2003

10 Marine Safety Victoria. A guide to the Marine regulations and how they affect you. Melbourne: Marine Safety Victoria, 2005.

11 Marine Safety Victoria. Use of personal flotation devices by recreational boaters in Victoria. Melbourne: Marine Safety Victoria, 2004.

12 Bugeja L. Recreational vessel fatalities in Victoria 1999-2002. Melbourne: State Coroner's Office, Victoria, 2003.

13 Mangione T, Rangel M, Watson K. National PFD wear observational study 2005. With comparison data from 1998 to 2004. Boston: JSI Research and Training Institute, 2005
14 Mangione T, Chow W. Changing life jacket wearing behaviour: an evaluation of two approaches. J Public Health Policy. Published Online First: 16 January 2014. doi:10.1057/jphp.2013.51

15 Cassell E, Ashby K. Personal Flotation Device wear rate study 2007. National Marine Safety Committee, 2007. http:/www.nmsc.gov.au/media/pages_media_files/files/ Research-\%20PFD\%20Wear\%20Rate\%20Study\%202007.pdf (accessed Oct 2012).

16 The Starr Group Inc. in association with SCS Consultants. National PFD observational wear rate study for the 2000 boating season. Canadian Coast Guard, 2001.

17 Karkhaneh M, Kalenga J-C, Hagel BE, et al. Effectiveness of bicycle helmet legislation to increase helmet use: a systematic review. Inj Prev 2006:12:76-82.

18 Cameron $\mathrm{MH}$, Vulcan AP, Finch CF, et al. Mandatory bicycling helmet use following a decade of helmet promotion in Victoria, Australia-an evaluation. Accid Anal Prev 1994;26:323-5.

19 Williams A, Wells JK. The role of enforcement programs in increasing seat belt use. J Safety Res 2004;35:175-80.

20 Quantum Market Research. Marine Safety Victoria new marine safety regulations. Qualitative and quantitative research findings. Report to Marine Safety Victoria, Melbourne, July 2006.

21 Bugeja L, Cassell E, Brodie LR, et al. Effectiveness of the 2005 compulsory personal flotation device (PFD) wearing regulations in reducing drowning deaths among recreational boaters in Victoria Australia. Inj Prev 2014;20: 387-92.

\section{Provider achieves $\mathbf{7 0} \%$ drop in workers' compensation claims}

Since introducing an injury prevention programme 5 years ago, Western Australian aged care provider, Amana Living, has had a 70\% reduction in workers compensation claims, making it among the lowest in the industry. Apparently the success reflects careful matching of competencies with the physical requirements of the job.

\section{Nine research centres for Olympic injury prevention}

The International Olympic Committee (IOC) announced that nine centres have been recognised as IOC Research Centers for Prevention of Injury and Protection of Athlete Health. The list includes institutions and hospitals from Australia, Canada, Denmark, South Korea, The Netherlands, Norway, Qatar, South Africa and Britain.

Editor's Comment: This seems a sensible idea, but I am curious to learn how these centres were chosen.

\section{Florida football player's hit-and-run reduced to traffic violation}

A Florida State football player left the crash scene after driving his car into the path of an oncoming vehicle. The local police and the University police investigated and concluded that in spite of driving with a suspended license, the player was not to be charged with a hit-and-run. No attempt was made to establish if alcohol was involved. The New York Times viewed these omissions as part of a pattern where Universities give preferential treatment to athletes. 